\title{
Bacterias del Ácido Láctico un Potencial para la Producción de Alimentos Probióticos Fermentados en la Industria Láctea de Panamá
}

\section{Melvys Jacqueline Vega Quintero}

Universidad Tecnológica de Panamá, Centro de Producción e Investigaciones Agroindustriales (CEPIA), Panamá, República de Panamá

\section{Abstract}

The lactic acid bacteria known by their initials (BAL) are microorganisms that in the absence of oxygen degrade carbohydrates like lactose (milk sugar), to synthesize lactic acid and energy, through a process known as lactic fermentation. In the dairy industry these microorganisms are used as lactic ferments or initiators of the lactic

Corresponding Author: Melvys Jacqueline Vega Quintero

melvys.vega@utp.ac.pa

Received: 15 November 2017

Accepted: 5 January 2018

Published: 4 February 2018

Publishing services provided by Knowledge $\mathrm{E}$

(c) Melvys Jacqueline Vega Quintero. This article is

distributed under the terms of the Creative Commons

Attribution License, which permits unrestricted use and redistribution provided that the original author and source are credited.

Selection and Peer-review under the responsibility of the ESTEC Conference Committee.

G OPEN ACCESS fermentation process for the manufacture of cheeses, yogurt, fermented milk and other products derived from milk. The type of bacterial species used as an initiator in the fermentation process is a determining factor in the nutritional quality and sensorial characteristics of the final product. The main objective of the investigation is to carry out an evaluation on the potential of sources and milk production in Panama, specifically in the Chiriquí Highlands. Regarding the scope of the research, its perspective is to continue research on the biological diversity of lactic acid bacteria present in dairy sources, for their isolation and use in the dairy industries. It is important to highlight the high production of cattle, sources and milk production in the Highlands, which represents a potential diversity of lactic acid bacteria.

Keywords: Lactic acid bacteria, lactic fermentation, probiotic foods, genetic markers, phenotype.

\section{Resumen}

Las bacterias del ácido láctico conocidas por su siglas (BAL) son microorganismos que en ausencia de oxígeno degradan carbohidratos como la lactosa (azúcar de leche), para sintetizar ácido láctico y energía, a través de un proceso conocido como fermentación láctica. En la industria láctea estos microorganismos son utilizados como fermentos lácticos o iniciadores del proceso de fermentación láctica para la fabricación de quesos, yogurt, leche fermentada y otros productos derivados de la leche. El tipo de especie bateriana que se utiliza como iniciador en el proceso de fermentación, 
constituye un factor determinante en la calidad nutritiva y características sensoriales del producto final. El objetivo principal de la investigación es realizar una evaluación sobre el potencial de fuentes y producción de leche en Panamá, específicamente en las Tierras Altas de Chiriquí. Con relación al alcance de la investigación, su perspectiva es continuar con investigaciones sobre la diversidad biológica de las bacterias del ácido láctico presentes en las fuentes de lechería, para su aislamiento y utilización en las industrias lácteas. Cabe destacar como hallazgo la alta producción de ganado bovino, fuentes y producción de leche en las Tierras Altas, lo cual supone un potencial de diversidad de bacterias del ácido láctico.

Palabras claves: Bacterias del ácido láctico, fermentación láctica, alimentos probióticos, marcadores genéticos, fenotipo.

\section{Introduction}

El presente trabajo de investigación se centró en el análisis de la producción de leche en Panamá, específicamente en el Distrito de las Tierras Altas de Chiriquí, las fuentes lecheras y las características del área de estudio, con el objetivo de desarrollar estudios posteriores sobre la diversidad de bacterias del ácido láctico, sus características físicoquímicas y biología molecular. El trabajo constituye un componente, resumen y avance de un proyecto de investigación que se realiza en el Centro de Producción e Investigaciones Agroindustriales (CEPIA) de la Universidad Tecnológica de Panamá, sobre el potencial de las bacterias del;ácido láctico como fermentos lácticos probióticos, para la elaboración de alimentos derivados de la leche en la industria láctea de Panamá. La finalidad del proyecto es proporcionar la seguridad alimentaria en zonas urbanas y rurales en el país, con productos lácteos probióticos, de calidad, funcionales y de amplia vida útil, es decir, garantizar la disponibilidad de alimentos proteínicos de origen lácteo, el acceso a la diversidad de productos derivados de la leche, el aprovechamiento biológico y su comercialización. El aporte de la investigación al conocimiento sobre los fermentos lácticos probióticos, radica en el desarrollo de nuevos modelos de procesamiento de alimentos optimizados en la industria láctea en la elaboración de productos lácteos de calidad y funcionales.

Los fermentos lácticos probióticos identificados, generarán impactos económicos, sociales y ambientales.

Entre los impactos económicos la reducción de tiempos y costos de producción en la industria láctea, mayor producción y disponibilidad de alimentos lácteos probióticos, 
incremento en la inversión privada para desarrollo de la industria alimenticia, mayor inversión privada en la investigación en ciencia, tecnología e innovación. En cuanto a los impactos sociales, generará cambios en los hábitos alimenticios de productos lácteos, incremento del bienestar físico y mental de los consumidores, balance y equilibrio de la microbiota intestinal de los individuos, incremento de producción intelectual en el área de la Agroindustria de Panamá, cambios en la educación superior sobre los paradigmas tradicionales en la ingeniería de alimentos y aumento de interés por el desarrollo de la investigación científica en el área de alimentos lácteos. Por último, generará impactos ambientales como cambios en los usos de tecnologías en los procesos industriales, incremento en la aplicación de nuevas tecnologías sostenibles y limpias, desarrollo sostenible de la biodiversidad microbiológica aplicada a la industria láctea.

Los productos lácteos o derivados lácteos, incluye alimentos como la leche y sus derivados procesados (generalmente fermentados) y son tratados por diversos procesos en las industrias denominadas Industrias Lácteas. Las plantas industriales se caracterizan por la manipulación de un producto altamente perecedero, como la leche, que debe vigilarse y analizarse correctamente durante todos los pasos de la cadena de frío hasta su llegada al consumidor.

La leche empleada mayoritariamente en la elaboración de los productos procede del ganado vacuno o bovino, aunque también puede consumirse leche procedente de otros mamíferos tales como: el caprino y ovino, en algunos países, la búfala, la camella, la yak y la yegua.

En la actualidad la mayor parte de los alimentos probióticos y funcionales se elaboran a partir de la leche. El consumo de productos lácteos ha experimentado, desde la década de 1950, un considerable crecimiento en la demanda mundial que ha llevado a la industria a superar retos tecnológicos importantes.

La República de Panamá tiene antecedentes históricos de actividad ganadera para la lechería y carne, muy marcada y tradicional. La actividad de lechería fue inducida desde la época de la colonia y la producción ha evolucionado desde la artesanal hasta la industrializada. Hoy en día la tecnología se utiliza en el procesamiento de la materia prima (leche) a otros productos lácteos como la mantequilla, quesos, yogurt y otros, los cuales son fabricados en industrias panameñas.

De acuerdo con estudios realizados por Montero, E., 2013, Panamá ocupa el sexto lugar en Centroamérica con $5 \%$ de producción de lechería y está concentrado en el abastecimiento del mercado panameño. 
El análisis de la producción de leche en Panamá, específicamente en el Distrito de las Tierras Altas de Chiriquí, fue realizado con base en información recabada en campo (encuestas, entrevistas y observación in situ) y datos del último Censo Agropecuario realizado en Panamá en el año 2011.

\section{2. Área de Estudio}

La zona de estudio la constituye el Distrito de Tierras Altas, el cual se localiza en la provincia de Chiriquí República de Panamá, en la Cuenca Hidrográfica No. 102 denominada Chiriquí Viejo (cuenca media y alta). Ver figura No. 1. Está conformada por los Corregimientos: Volcán, Cerro Punta, Cuesta de Piedra, Nueva California y Paso Ancho. Se caracteriza por su zona de vida bosque muy húmedo con $43.26 \%$ de la superficie y bosque húmedo tropical con $15.93 \%$. Comprende clima oceánico de montaña y clima tropical de montaña media y alta. Los suelos de textura mimosa, color chocolate oscuro, formas irregulares con alta permeabilidad. La precipitación media anual de la cuenca es de 3,322 mm.

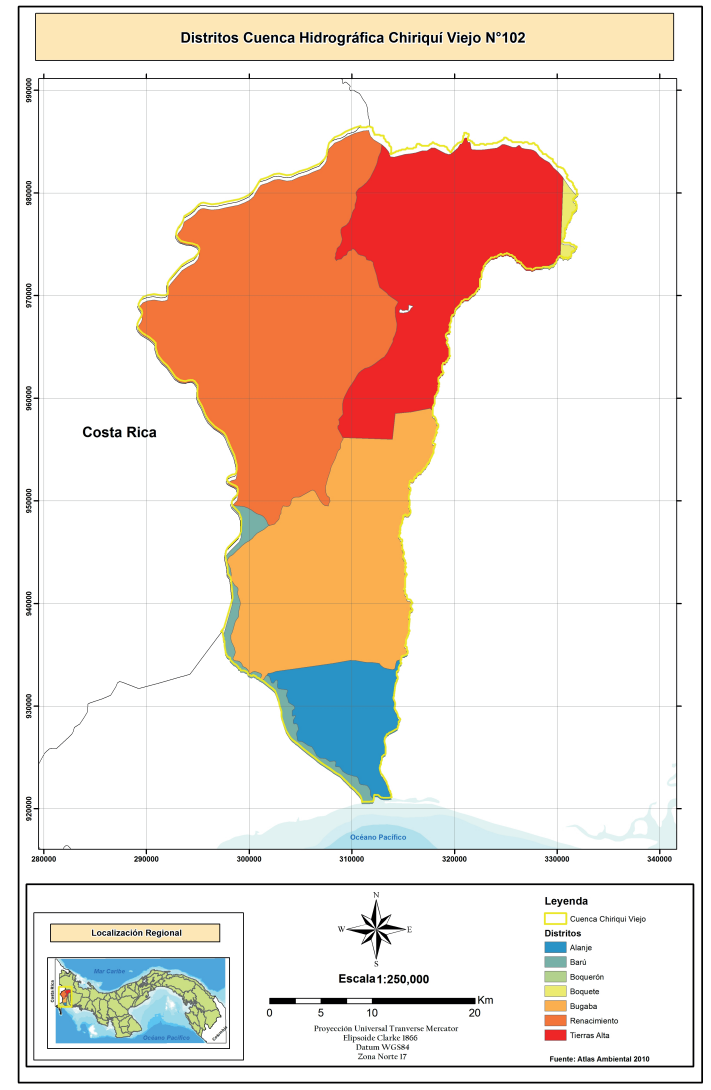

Figura 1: Distrito de Tierras Altas en la Cuenca Hidrográfica del Río Chiriquí Viejo. 


\section{Materiales y Métodos}

Se realizó inpección en la zona de estudio, se tomaron datos de campo a través de observaciones in situ, encuestas y se realizaron entrevistas con proveedores de leche de las industrias lácteas. Se recopiló información sobre la cantidad, tipo y características de las fuentes lecheras. Se recabó información en las fuentes institucionales de competencia y empresas relacionadas con la producción de leche bovina. También se recopiló información sobre las características biogeográficas del área de estudio. Se validó la información obtenida, se procesó los datos y se analizó la información, a través de la estadística (cuadros y gráficos). Se elaboró la cartografía del área de estudio, a través de Sistema de Información Geográfica (SIG), cuyos datos fueron tomados en campo.

\section{Resultados y Discusión}

\subsection{Análisis de la Producción de Ganado Bovino, Nivel Nacional}

La cría de ganado bovino es la actividad pecuaria más significativa que se practica en Panamá, con fines de producción de leche, carne y genética. La materia prima que se genera como la leche y carne constituyen los principales insumos para la industria y la fabricación de productos lácteos derivados. La producción de la materia prima depende de la población de ganado bovino que han generado los productores de ganado.

Durante el período de 1993 a 2013, la población de ganado bovino aumentó progresivamente y de acuerdo con su distribución por provincia, Chiriquí es la provincia con mayor población de bovinos, luego Los Santos y Veraguas. Las Comarcas y la provincia de Bocas del Toro son las que tienen menor población de ganado bovino. Ver figura 2.

La población de ganado bovino, se distribuye en tres tipos: Cría (genética), leche (productos lácteos) y ceba (carne). La cría (genética) es la más representativa, seguido de la carne y por último lechería. En el año 2013, la cantidad de cabezas de ganado bovino existente, proporcionó la disponibilidad, la sostenibilidad de alimentos para la población y aseguró la continuidad en las generaciones futuras. Ver tabla 1. 


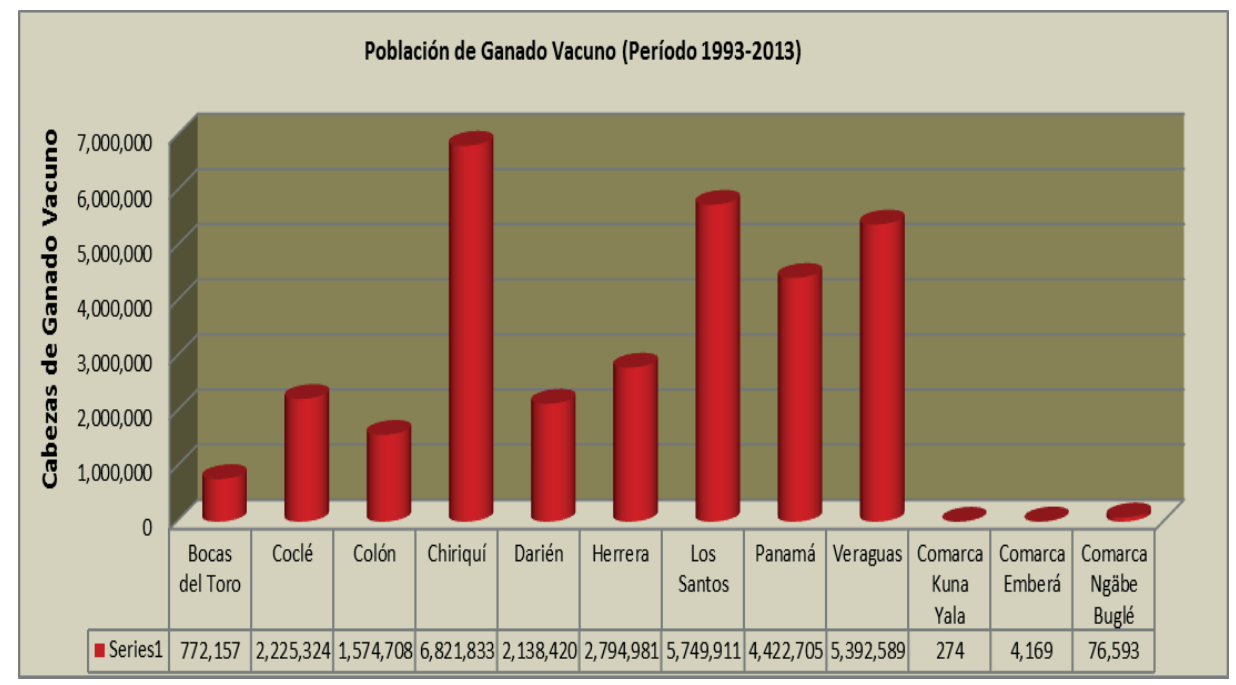

Figura 2: Población de Ganado Bovino (Período 1993-2013. Fuente: Contraloría General de la República de Panamá. 2013. "Censo Agropecuario de 24 de abril al 1 de mayo de 2011". Compendio de Años 1993 2013.

TABLA 1: Población de Ganado Bovino por Región y por Tipo.

Año 2013

\begin{tabular}{|c|c|c|c|c|}
\hline \multirow{3}{*}{$\begin{array}{c}\text { Provincia y } \\
\text { comarca } \\
\text { indígena }\end{array}$} & \multicolumn{4}{|c|}{ Existencia de ganado vacuno (en cabezas) } \\
\hline & \multirow{2}{*}{ Total } & \multicolumn{3}{|c|}{ Actividad principal de la } \\
\hline & & Cría & Leche & Ceba \\
\hline TOTAL & $\mathbf{1 , 7 2 5 , 8 0 0}$ & $1,151,600$ & 225,100 & 349,100 \\
\hline Bocas del Toro & 53,200 & 45,700 & 1,200 & 6,300 \\
\hline Coclé & 120,000 & 88,500 & 12,600 & 18,900 \\
\hline Colón & 83,800 & 67,400 & 2,100 & 14,300 \\
\hline Chiriquí & 346,300 & 190,500 & 86,300 & 69,500 \\
\hline Darién & 221,500 & 140,400 & 2,100 & 79,000 \\
\hline Herrera & 101,000 & 49,500 & 38,000 & 13,500 \\
\hline Los Santos & 243,500 & 150,100 & 38,900 & 54,500 \\
\hline Panamá & 267,400 & 196,700 & 20,200 & 50,500 \\
\hline Veraguas & 268,400 & 204,600 & 22,800 & 41,000 \\
\hline $\begin{array}{l}\text { Comarca Ngäbe } \\
\text { Buglé }\end{array}$ & 20,700 & 18,200 & 900 & 1,600 \\
\hline
\end{tabular}

Fuente: Contraloría General de la República de Panamá. 2013. “Censo Agropecuario de 24 de abril al 1 de mayo de 2011". Compendio de Años 1993 - 2013.

\subsection{Análisis de Producción de Leche por Año, Nivel Nacional}

La producción de leche durante el período de 1992 a 2005 se califica moderadamente fluctuante con tasa de crecimiento sostenida y dinámica. El máximo nivel del período se obtuvo en el año 2005 y el mínimo en 1992. El análisis revela que la dinámica de producción de leche se caracteriza por su tendencia creciente y su fluctuación se mantiene moderada, sin caídas abruptas en el período estudiado (ver figura 3).

Se deduce que la producción de leche está asociada al crecimiento de la población de ganado bovino, a los cambios considerables en la producción lechera a largo plazo, 
los cuales han abierto nuevas rutas de recolección, con nuevos centros de acopio y las empresas aumentan aceleradamente su recepción, se mejora la calidad de la materia prima y de los productos elaborados.

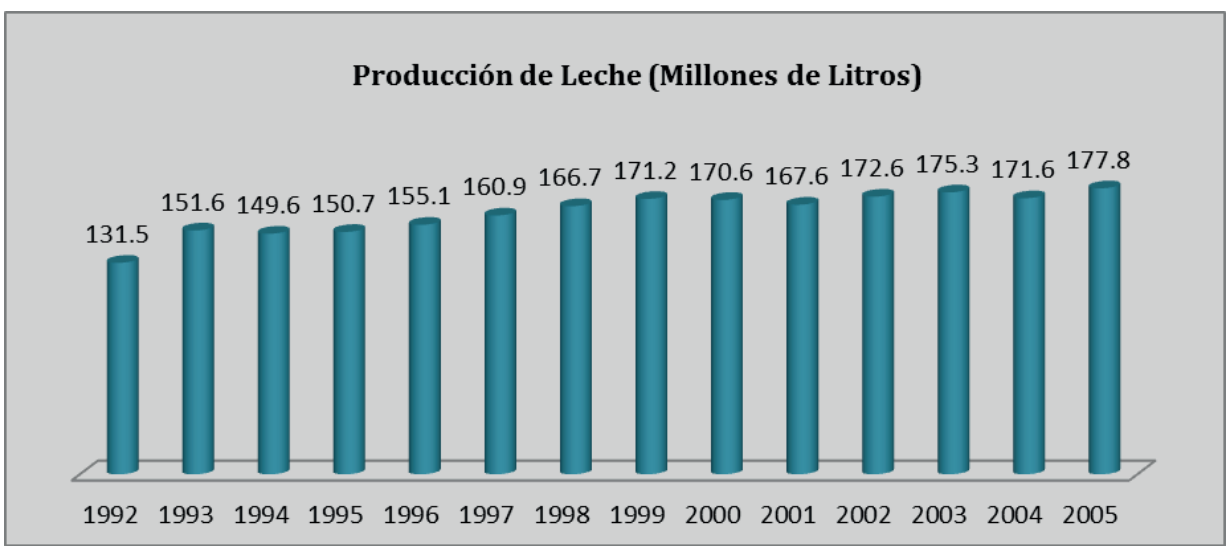

Figura 3: Producción de Leche Nivel Nacional por Año. Fuente: Contraloría General de la República de Panamá. 2003 (a). "Situación Económica, Producción Pecuaria Años 1991 -2002". Estimación de la Dirección Nacional de Ganadería, Ministerio de Desarrollo Agropecuario (MIDA) / Contraloría General de la República de Panamá. 2003 (b). "Situación Económica, Producción Pecuaria Años 2004 - 2005". Estimación Dirección Nacional de Ganadería, Ministerio de Desarrollo Agropecuario (MIDA).

\subsection{Análisis de Producción de Leche por Tipo de Tecnologías, Nivel Nacional}

La legislación en Panamá, tipifica la producción de leche en tres tipos de Leche: $A$, B, C. En la actualidad existen 6,520 productores de leche Grado A con las mejores tecnologías, que venden su leche a las industrias, la mayor cantidad se localiza en la provincia de Los Santos con 2,437 proveedores, seguido de la provincia de Chiriquí con 1,651 y Herrera con 1,577 proveedores.

En menor incidencia se encuentran las tecnologías intermedias de producción de leche Grado B, con 240 proveedores de la industria, distribuidas en 209 proveedores en Chiriquí y 16 en Herrera. Por último, la producción de leche sin tecnologías Grado C con 90 proveedores de leche, la cual se concentra en Veraguas con 364 proveedores y 47 en Panamá. Ver Tabla 2.

\subsection{Análisis de Producción de Leche en las Tierras Altas de Chiriquí}

La producción de leche en las Tierras Altas de Chiriquí es aproximadamente de 39 millones de litros anuales. Los corregimientos de mayor producción corresponden a Bugaba (cabecera) y Volcán con 10,274, 976 y 12,477, 696 litros respectivamente (ver tabla 3). El Corregimiento de Bugaba es considerado como la zona de mayor producción 
TABla 2: Proveedores, por Provincia y Tipo de Leche. Año 2005.

\begin{tabular}{|c|c|c|c|c|}
\hline PROVINCIA & GRADO A & $\begin{array}{c}\text { GRADO } \\
\text { B }\end{array}$ & $\begin{array}{c}\text { GRADO } \\
\text { C }\end{array}$ & TOTAL \\
\hline Bocas del Toro & 26 & & & 26 \\
\hline Coclé & 146 & 3 & 0 & 143 \\
\hline Colón & 34 & 0 & 0 & 34 \\
\hline Chiriquí & 1,651 & 209 & 3 & 1,439 \\
\hline Herrera & 1,577 & 16 & 23 & 1,538 \\
\hline Los Santos & 2,437 & 0 & 0 & 2,437 \\
\hline Panamá & 280 & 7 & 47 & 117 \\
\hline Veraguas & 369 & 5 & 364 & 105 \\
\hline TOTAL & 6,520 & 240 & 90 & 6,190 \\
\hline
\end{tabular}

TABLA 3: Producción de Leche en la Tierras Altas de Chiriquí.

Año 2011

\begin{tabular}{|l|c|c|r|}
\hline \multicolumn{4}{|c|}{ Producción de Leche Distrito de Bugaba y Tierras Altas. } \\
\hline Corregimientos & Litros / Semana & Litros por Mes & \multicolumn{1}{c|}{ Litros por Año } \\
\hline La concepción (Cabecera) & 214,062 & 856,248 & $10,274,976$ \\
\hline Aserrío de geriché & 52,197 & 208,788 & $2,505,456$ \\
\hline Bugaba & 10,838 & 43,352 & 520,224 \\
\hline Cerro Punta & 3,029 & 12,116 & 145,392 \\
\hline Gómez & 25,082 & 100,328 & $1,203,936$ \\
\hline La Estrella & 24,759 & 99,036 & $1,188,432$ \\
\hline San Andrés & 33,277 & 133,108 & $1,597,296$ \\
\hline Santa Marta & 43,321 & 173,284 & $2,079,408$ \\
\hline Santa Rosa & 53,435 & 213,740 & $2,564,880$ \\
\hline Santo Domingo & 16,672 & 66,688 & 800,256 \\
\hline Sortová & 33,536 & 134,144 & $1,609,728$ \\
\hline Volcán & 259,952 & $1,039,808$ & $12,477,696$ \\
\hline El Bongo & 25,553 & 102,212 & $1,226,544$ \\
\hline Total Litros & & & $\mathbf{3 8 , 1 9 4 , 2 2 4}$ \\
\hline Valor Total (Balboas) & 344,529 & $1,378,116$ & $\mathbf{1 6 , 5 3 7 , 3 9 2}$ \\
\hline
\end{tabular}

Fuente: Contraloría General de la República. Censo Agropecuario de 24 de abril al 1 de mayo de 2011.

de leche en la provincia. El movimiento económico que genera las Tierras Altas en producción de leche corresponde a más de más de 16 millones de dólares de manera directa e indirecta. 


\subsection{Análisis de Producción de Leche, según Tecnología Utilizada en las Tierras Altas de Chiriquí}

En las Tierras Altas de Chiriquí se aplica tres tipos de tecnologías para la producción de leche: la alta tecnología el cual produce la leche Grado A, la tecnología intermedia el cual produce la leche Grado B y la tecnología manual el cual produce la leche Grado C. La producción total anual de leche en la zona, según su tecnología corresponde a 6,144 litros Grado A; 4,800 litros Grado B y 27,504 litros Grado C.

Los Corregimientos de mayor producción de leche Grado A es Concepción y Volcan; Cerro Punta y Santo Domingo se sitúan como áreas de mínima producción. Con relación a la producción Grado B los mayores productores corresponden a los Corregimientos de Aserrío de Geriché y Santa Marta y en menor incidencia de producción los Corregimientos de Volcán y Cerro Punta. En cuanto a la producción de leche grado C, los Corregimientos de mayor producción son Aserrío de Geriché y la Estrella y en menor producción el Corregimiento de Cerro Punta. Ver figura 4.

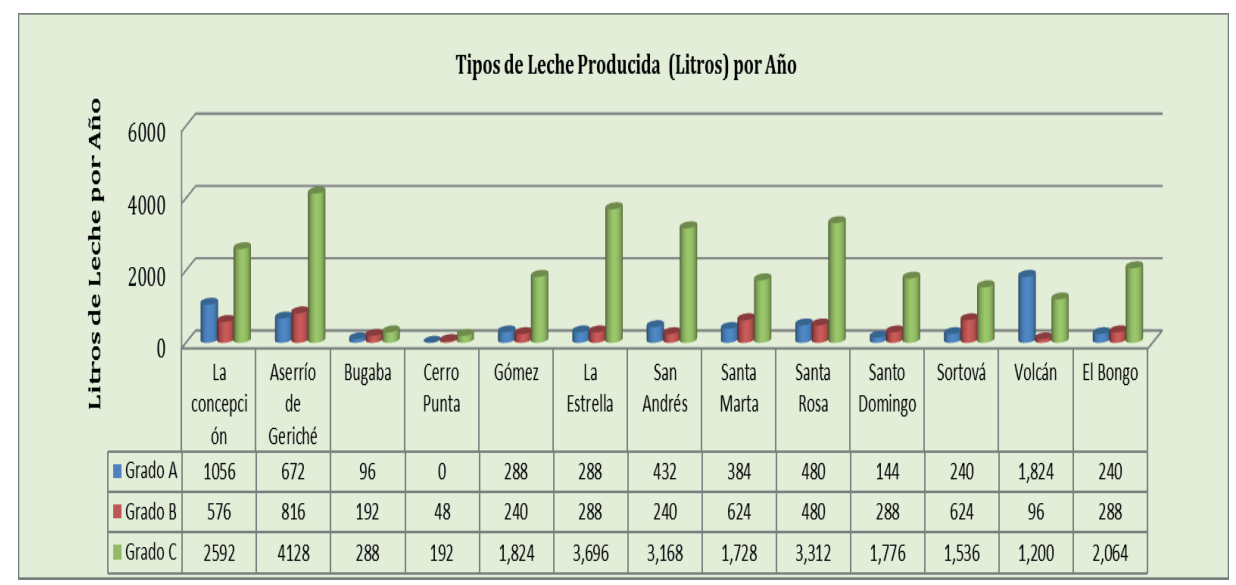

Figura 4: Producción de leche (litros). Año 2011. Fuente: Contraloría General de la República. Censo Agropecuario de 24 de abril al 1 de Mayo de 2011.

\section{CONCLUSIONES}

- La producción de ganado bovino a nivel nacional revela sostenibilidad en la década de 2000, su crecimiento se concentra en la provincia de Chiriquí y el potencial de desarrollo económico se identifica en la producción de leche en las Tierras Altas. 
- Las características y condiciones biogeográficas de las Tierras Altas de Chiriquí, favorecieron el crecimiento de la población de ganado bovino y por ende la producción de leche.

- Se reconoce el potencial de fuentes de leche en las Tierras Altas de Chiriquí y por tanto, la existencia de un acervo genético y diversidad biológica de bacterias del ácido láctico aptas como fermentos lácticos probióticos en la industria Láctea.

\section{Referencias}

[1] Contraloría General de la República de Panamá. 2013. "Censo Agropecuario de 24 de abril al 1 de mayo de 2011". Compendio de Años 1993 - 2013. Panamá República de Panamá. https://www.contraloria.gob.pa

[2] Contraloría General de la República de Panamá. 2003. "Situación Económica, Producción Pecuaria Años 1991 -2002". Estimación de la Dirección Nacional de Ganadería, Ministerio de Desarrollo Agropecuario (MIDA). https://www.contraloria.gob.pa

[3] Contraloría General de la República de Panamá. 2003. Situación Económica, Producción Pecuaria Años 2004 - 2005. Estimación Dirección Nacional de Ganadería, Ministerio de Desarrollo Agropecuario (MIDA). https://www.contraloria.gob.pa

[4] Ministerio de Desarrollo Agropecuario. 2007. "Estadística de Productores de Leche por Tipo". Oficina de Programación y Evaluación, DINAG - MIDA. https://www.mida.gob.pa.

[5] MONTERO, E. 2013. "Situación Actual y Perspectivas del Sector Lácteo a Nivel Mundial". Congreso Nacional Lechero 2013. Cámara Nacional de Productores de Leche. Costa Rica. 2013. 50 p.p. 